Provided for non-commercial research and education use. Not for reproduction, distribution or commercial use.

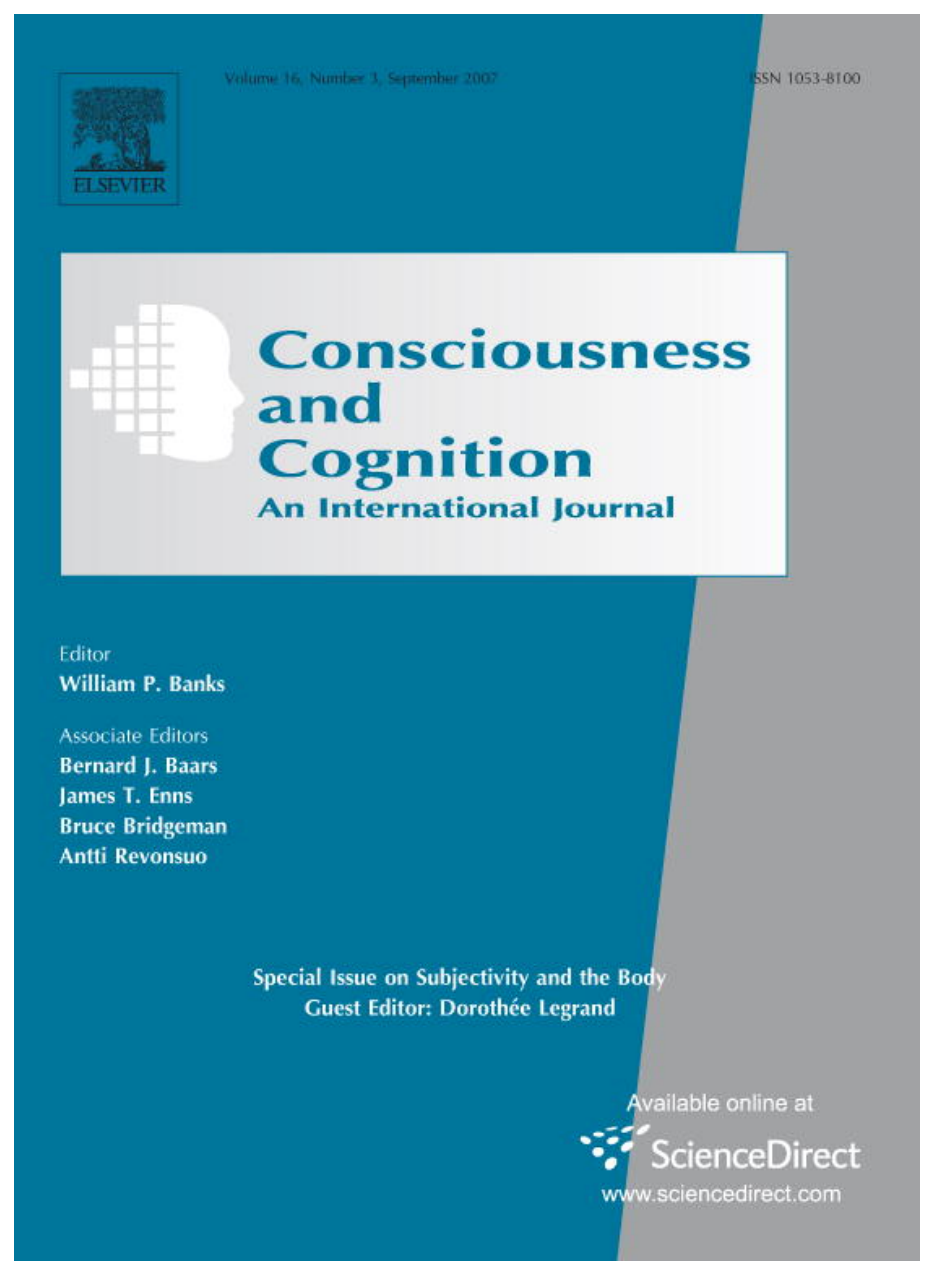

This article was published in an Elsevier journal. The attached copy

is furnished to the author for non-commercial research and education use, including for instruction at the author's institution, sharing with colleagues and providing to institution administration.

Other uses, including reproduction and distribution, or selling or licensing copies, or posting to personal, institutional or third party websites are prohibited.

In most cases authors are permitted to post their version of the article (e.g. in Word or Tex form) to their personal website or institutional repository. Authors requiring further information regarding Elsevier's archiving and manuscript policies are encouraged to visit:

http://www.elsevier.com/copyright 
Consciousness

and

Cognition

www.elsevier.com/locate/concog

\title{
Mountains and valleys: Binocular rivalry and the flow of experience
}

\author{
Diego Cosmelli ${ }^{\text {a }}$, Evan Thompson ${ }^{\mathrm{b}, *}$ \\ ${ }^{a}$ Laboratorio de Neurociencias Cognitivas, Departamento de Psiquiatría, Pontificia Universidad Católica de Chile, Marcoleta 391, \\ Santiago de Chile, Chile \\ ${ }^{\mathrm{b}}$ Department of Philosophy, University of Toronto, University College, 15 King's College Circle, Toronto, Ont., Canada M5S $3 H 7$
}

Received 28 December 2006

Available online 4 September 2007

\begin{abstract}
Binocular rivalry provides a useful situation for studying the relation between the temporal flow of conscious experience and the temporal dynamics of neural activity. After proposing a phenomenological framework for understanding temporal aspects of consciousness, we review experimental research on multistable perception and binocular rivalry, singling out various methodological, theoretical, and empirical aspects of this research relevant to studying the flow of experience. We then review an experimental study from our group explicitly concerned with relating the temporal dynamics of rivalrous experience to the temporal dynamics of cortical activity. Drawing attention to the importance of dealing with ongoing activity and its inherent changing nature at both phenomenological and neurodynamical levels, we argue that the notions of recurrence and variability are pertinent to understanding rivalry in particular and the flow of experience in general. (C) 2007 Elsevier Inc. All rights reserved.
\end{abstract}

Keywords: Binocular rivalry; Multistable perception; Metastability; Cortical dynamics; Neurophenomenology

\section{Introduction}

When two different patterns are presented simultaneously, one to each eye, they seem to alternate back and forth at irregular intervals, a phenomenon known as binocular rivalry. This paper explores how binocular rivalry can be used to investigate the temporal structure and dynamics of the ongoing flow of conscious experience.

Binocular rivalry has received considerable attention from neuroscientists for several reasons (Blake \& Logothetis, 2002). First, it is an intriguing experience in itself. How is it that this perceptual alternation comes about? Why do we not see either a static mixture of two images or both images at the same time, one superimposed on the other? Second, binocular rivalry has been proposed as a way to identify those neural processes that correlate directly with visual consciousness (Crick, 1996). Because the same stimulus alternates between being consciously perceivable and unperceivable, depending only on the subject's internal state, we can

\footnotetext{
* Corresponding author. Fax: +1 4169712027.

E-mail addresses: dcosmelli@uc.cl (D. Cosmelli), evan.thompson@utoronto.ca (E. Thompson).
} 
compare the neurobiological state of the subject while he is conscious of the stimulus and while he is not. Finally, it has been suggested that such perceptual alternation might share biological substrates with attention and reflect basic mechanisms that secure an ongoing perceptual "sampling" of the available world (Leopold \& Logothetis, 1999).

Yet binocular rivalry can also been seen in the context of the ongoing dynamics of the experience it reveals. We see one possible image, transit to the alternative, hold it for a moment, transit back again, and so on. This invariant structure holds true for the perception of many ambiguous figures, but is also relevant to general considerations about the temporal dynamics of the flow of subjective experience (Cosmelli, Lachaux, \& Thompson, 2007).

This paper explores this idea. Using binocular rivalry as a paradigm, we propose some new theoretical and methodological tools for the neuroscientific study of the temporal dynamics of the ongoing flow of subjective experience.

The approach we take here belongs to the research program known as neurophenomenology (Lutz \& Thompson, 2003; Varela, 1996). Neurophenomenology uses phenomenological investigations of the phenomenal structure of subjective experience to guide neuroscientific investigations of the brain activity subserving consciousness (see, e.g., Lutz, Lachaux, Martinerie, \& Varela, 2002; Rainville \& Price, 2003). Our specific concern in this paper is with how phenomenological analyses of the temporality of consciousness can benefit neuroscientific studies of the temporal dynamics of the brain activity associated with the ongoing flow of experience.

We begin in Section 2 with some phenomenological considerations about the temporality of consciousness. These considerations provide a conceptual and phenomenological framework for our discussion of binocular rivalry. We then review some of the extant literature on rivalry, with emphasis on recent experimental work by our group that takes a neurophenomenological approach. Finally, we explore the implications of this work for advancing the neuroscientific study of the ongoing flow of experience.

\section{A phenomenological framework}

During both unreflective everyday experience (walking the dog, watching the rain fall, daydreaming, etc.) and more constrained mental activity (self-conscious reflection, attentive concentration, etc.), the dynamical aspect of our conscious experience is pervasive and unavoidable. Whether we are startled by a unique and surprising event, such as a thunder clap, or we are following the ongoing train of ideas during a lecture, our experience seems always to be on the move. Yet we can recognize not only an ongoing movement or flow, but also a certain standing now or present moment, which seems always there-or rather here - invariant throughout the flow. These two structural features of our experience - a standing now and an ongoing flow - are central to both James's (1981) and Husserl's (1991) analyses of consciousness. ${ }^{1}$ According to Husserl (1991), they form one unified phenomenal structure, which he calls the standing-streaming structure of time-consciousness (see Zahavi, 2003, 2005). To set forth a phenomenological framework for our treatment of binocular rivalry in this paper, let us highlight a few basic features of this phenomenal structure.

\subsection{Standing: The now}

The experience of time can be understood as the consciousness of things and events as temporal, as the awareness of them as enduring, changing, staying the same, and so on. This sort of consciousness would not be possible if our consciousness of the present moment were that of a punctual or instantaneous now. Rather, consciousness of the present moment must be of the present as having temporal width. In James's words, "the practically cognized present is no knife-edge," but instead a "duration-block," a temporal expanse containing past and future phases, "a bow and a stern... a forward- and rearward-looking part" (James, 1981, p. 574). Whereas James takes this duration-block or so-called specious present as a basic datum of experience, Husserl takes it as requiring further phenomenological analysis (Gallagher, 1998, pp. 32-52). More precisely,

\footnotetext{
${ }^{1}$ For further discussion, see Gallagher (1998), Thompson (2007), Varela (1999), and Zahavi (2003, 2005).
} 
the extended present, as a phenomenal content of consciousness, needs to be understood in relation to the type of intentionality that brings about or makes available this content.

According to Husserl (1991), the intentionality of time-consciousness has a threefold structure. Three intentional processes, called primal impression, retention, and protention, work together in any experience and cannot operate on their own apart from one another. Husserl's favorite example is listening to a melody. For each now-phase of the melody, each currently sounding note, there is a corresponding primal impression directed exclusively toward that now-phase. Primal impression makes no reference to either past or future, and so by itself is insufficient for the perception of the melody (and for the experience of any temporal object, no matter how brief its duration). Primal impression must be accompanied by retention and protention. Retention is directed toward the just-elapsed phase of the melody, the just-heard note, which although no longer actual, is still being heard in the mode of just-past. The note still subjectively sounds not because it is really present to consciousness; on the contrary, it is no longer actual. Rather, it is present only intentionally; it is mentally intended as just-past. Protention, on the other hand, is directed in a more indefinite way toward the immediate future, in this case toward the notes of the melody sensed as just-about-to-occur. Unlike retention, which is intentionally filled or determinate in content, protention is unfilled or indeterminate. This openness, however, does involve a sense of anticipation, for were the melody to stop abruptly or were a wrong note to sound, we would be surprised. It is always possible in principle for us to be surprised in this way, no matter what the content of our present experience, and thus our consciousness at any given moment always involves an open and forward-looking horizon.

The unified operation of protention, primal impression, and retention underlies our experience of the present moment as thick with duration. Primal impression is the continuous intending of the new, even if it be only the newly unchanging (as in the case of a continually sounding tone); retention is the continuous holding onto the present as slipping away and sinking into the past; and protention is the continuous going beyond the present as opening into the future. This threefold structure is invariant and present synchronically as a unified whole throughout the course of experience. Although the specific phenomenal contents of this structure change from moment to moment, the structure itself does not (unless consciousness suffers a radical breakdown).

\subsection{Streaming: The flow}

As just mentioned, our experience comprises not only the extended now as an invariant structure of awareness, but also constant movement, as the not-yet and about-to-happen come to pass and become the just-happened and no-more. A moment ago perhaps you were asking yourself whether the previous analysis made sense, now you are reading this sentence, and maybe in a moment you will decide to get up and take a break, while letting your mind wander elsewhere. In these and other ways, our awareness seems to be constantly on the move. James (1981) vividly captures this flowing quality with his famous metaphor of the stream of consciousness.

James distinguishes two important aspects of this flow-substantive, stable moments, in which one is actually conscious of something, and transitive, feeling moments, in which one passes from one content to another (James, 1981, chap. IX). He describes consciousness as like a bird's life, for it seems to be made up of an alternation of flights and perchings. James remarks that substantive moments can be recognized as such, whereas transitive moments are quite difficult to pinpoint accurately. They present themselves as tendencies and changes between states, and not as distinct contents immediately definable in themselves, save by some retrospective exercise.

Although this analysis captures a significant portion of the dynamics of ongoing experience, it tends to focus on the sequential character of substantive (perching) and transitive (flying) moments. Yet the substantive moments too are never static, for any momentary "perching" of consciousness is itself intrinsically labile and unstable (Cosmelli et al., 2007; Hanna \& Thompson, 2003), as we will see concretely later in this paper. The dynamics of consciousness thus lies deeper than simply its change of focus (Cosmelli et al., 2007).

\subsection{The living present as standing-streaming}

Let us synthesize these brief phenomenological considerations. Within ongoing experience we can distinguish between, on the one hand, the changing or varying contents of consciousness, and on the other hand, 


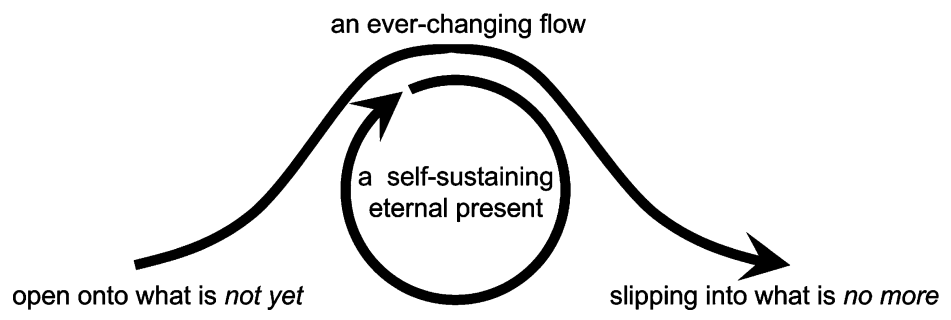

Fig. 1. The standing-streaming character of conscious experience.

how these contents appear, the mode or manner of their givenness. The particular contents of phenomenal consciousness change from moment to moment. But the way they appear - that they appear to flow or stream within a stretched-out now - does not change or vary; it remains invariant. In other words, the flowing or welling up of contents within a stretched-out now is an invariant structure of appearance. Although not itself any particular phenomenal content, it appears in them as an invariant phenomenal structure. Husserl calls this invariant structure the living present. The living present is the unified standing-streaming structure that results from the continual operation of primal impression-retention-protention. It is standing because it itself does not move in or through phenomenal time, being instead a basic structure of phenomenal time. It is streaming because it is the continuous transformation of the about-to-happen into the happening-now into the just-happened. This intentional transformation underlies any appearance of flow whatsoever (including the appearance of consciousness to itself as a subjective flow in so-called internal time-consciousness; see Zahavi, 2003, 2005) (see Fig. 1).

We propose that this analysis can have significant implications for the neuroscience of consciousness (see also Lloyd, 2002; Thompson, 2007; Varela, 1999; Vogeley \& Kupke, 2007). In particular, it suggests that we might try to approach the experimental study of consciousness by taking the unique phenomenal temporality of conscious experience as our reference point. In this way, phenomenological analysis might be able to guide and inform psychological and neurobiological investigations of consciousness.

\section{Multistable perception as an experimental approach}

Trying to study the standing-streaming structure of ongoing experience raises difficult experimental questions. How can we investigate the invariant flow of experience - understood as its standing-streaming character-rather than the changing contents of experience? Given the inherent variability of the spontaneous stream of mental activity, ${ }^{2}$ the situation poses a nontrivial methodological problem. How can we set up a properly controlled setting in order to investigate the structure of the ongoing flow as such rather than the myriad changing contents? Furthermore, given that this standing-streaming structure is supposed to be invariant across all conscious experience, we cannot proceed according to the classical scientific method of contrasting conditions in which the aspect under investigation is present with conditions in which it is absent. Thus what we need is some way to constrain the contents of experience so as to make evident how they are continuously modified through and by their ongoing flowing.

We propose that ambiguous or multistable perception paradigms offer a promising setting in which to approach this problem. These perceptual paradigms can be understood as highly constrained flow-of-experience situations, in which the possible contents of experience have been reduced to a small number (the conflicting perceptual alternatives). In other words, multistable perception offers a situation in which the invariant phenomenal form or structure of the flow as such (standing-streaming) can be made evident, precisely because the flowing contents are so highly constrained or restricted. From this perspective, our task is not to explain the particular contents of a given multistable perception situation, but rather to investigate the way these contents are phenomenally modified in time. In this way, we can focus on the structure of the ongoing flow, using

\footnotetext{
${ }^{2}$ Although we are quite good at recognizing what we have seen before, we do not experience something in exactly the same way twice. Furthermore, if somehow this happened, we would be in no position to distinguish both events.
} 

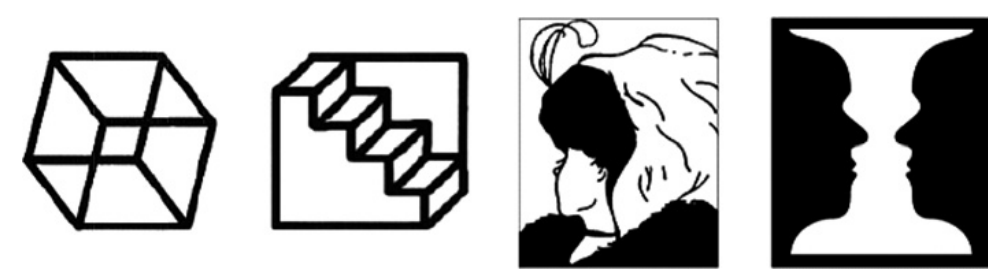

Fig. 2. From left to right: Necker cube, Schroeder staircase, My wife and my mother-in-law and Rubin's vase.

multistable perception as a model or study case. In the rest of this section, we review some of the general features of multistable perception from this perspective.

When viewed continuously, certain visual patterns produce a sequence of alternating perceptual interpretations. Such perceptual oscillations persist as long as the figures are viewed, and they occur in the absence of any physical change in the stimuli. The first published evidence of such multistable visual phenomena can be traced back quite far in the history of vision science. In 1760 Dutour described a phenomenon, which after Wheatstone's work in 1838, would be known as binocular rivalry. In 1832 Necker observed in viewing a crystal that at least two interpretations were possible. From his work issued the well-known Necker cube, perhaps the paradigm multistable figure. In 1915, Rubin introduced what eventually became known as the Rubin vase. Many other multistable visual phenomena have subsequently been described (Fig. 2).

In general, multistable phenomena exhibit a certain distribution of "residence" times on each possible interpretation. Perceptual dominance durations are distributed unimodally with a sharp growth and a long tail. They have typically been fitted to gamma distributions (Leopold \& Logothetis, 1996) or log-normal distributions (Lehky, 1995). Average reversion rate may vary from approximately 1 to $6 \mathrm{~s}$, depending on the pattern and the conditions used (Ditzinger \& Haken, 1989). ${ }^{3}$ Nevertheless, no short term autocorrelation has been found in the time series (Lehky, 1995). Therefore, although we know what the probability distribution will look like, we cannot predict the duration of a given dominance period based on preceding events.

Although the alternation among perceptual interpretations is essentially spontaneous, the dominance times of a given interpretation can be strongly influenced by a diversity of factors. Changes in stimulus contrast, luminance, and orientation can modify how long one given interpretation will remain. Furthermore, these factors are not restricted to low-level characteristics of the stimulus: surrounding context, contour completion, recognizability, and semantic content can bias in favor of one interpretation (Alais \& Blake, 1999; Blake, 1989; Kovacs, Papathomas, Yang, \& Feher, 1996). Voluntary control can also be exerted at various levels (Carter et al., 2005; Windman, Wehrmann, Calabrese, \& Güntürkün, 2006). One can intentionally favor which interpretation is preferentially retained (though not absolutely) and modify the rate of alternation to a significant degree (fast versus slow transitions). Attention to various aspects, either semantic or positional in the ambiguous figures, can also determine which interpretation dominates longer.

Another interesting point about multistable phenomena is that their temporal randomness can also be found in exploratory behaviors, such as free viewing or eye movements during cognitive tasks. In these behaviors, no low- or high-order correlation is found between successive fixation times, and the same type of distribution in residence times is observed (Leopold \& Logothetis, 1999).

Multistable phenomena therefore exhibit at least four fundamental characteristics: (i) a dynamic, multiple perceptual experience; (ii) exclusivity, i.e., only one possible interpretation is present at one time and in one point of the perceived space; (iii) spontaneity, meaning that transitions among perceptual interpretations occur whether the observer wants them to or not (although one can introduce bias voluntarily); and (iv) randomness, so that one cannot predict the future duration of a dominance period based upon previous periods.

Somewhat analogously, (i) during our daily ongoing conscious lives, we can choose among multiple views, thoughts, and actions, but when we hold onto any given one it fills momentarily our experience as a coherent whole; (ii) this dynamic ongoing experience appears exclusive, so that we do not normally experience two different objects (or thoughts or conscious states) at the same time and place; (iii) in this stream of conscious moments we transit from one content to another one spontaneously, though we can also direct the flow to

\footnotetext{
${ }^{3}$ Shorter and longer periods also occur for certain figures (Kelso, 1995).
} 
a greater or lesser extent; (iv) finally, as suggested by the temporal distribution of successive fixations, our "scanning" of the world apparently proceeds in an unpredictable manner.

These considerations suggest that multistable perception can be described as a case of a constrained flow of experience, and thus that it offers a model or study case for investigating the flow of ongoing experience, as proposed above.

\section{Binocular rivalry}

\subsection{The experience}

When corresponding regions of the retina of the two eyes are shown two different patterns that cannot be fused, the stimuli alternate as contents of conscious perception. This perceptual alternation is known as binocular rivalry and is one of the most interesting cases of multistable perception. In general, rivalry shares all the aforementioned dynamic characteristics of multistable perception, except that it happens between non-fusible stimuli that are projected independently to each eye, so that it is the outcome of a highly constrained situation. Rivalry is exclusive (only one image is seen) when and where it happens, but the zone of exclusive rivalry depends strongly on the size of the stimulus. ${ }^{4}$ When viewing large stimuli, a patchwork pattern of dominance may arise that is known as mosaic rivalry.

Dutour gave the first description of rivalry in 1760 when he noted alternations in perceived color when two different colors were viewed by each eye. Yet the phenomenon was not studied systematically until 1838, when Wheatstone, in his seminal work on stereopsis, published the first stereogram demonstrating contour rivalry. The next step was taken by Breese in two monographs in 1899 and 1909. In a series of rigorous observations of his own perception, Breese described accurately most stimulus determinants of rivalry (many of which still hold today), and exhaustively reported dominance times in different viewing and stimulation conditions (Breese, 1909).

The renewed neuroscientific interest in binocular rivalry has much to do with the re-emergence of consciousness as a valid scientific issue. One of the central questions in the neuroscience of consciousness is which neural processes correlate directly with conscious visual awareness of a given stimulus (in contrast with unconscious visual discrimination). Because one image is consciously perceived in binocular rivalry while the other is not, it seems possible to address this question using this experimental paradigm. By contrasting the brain patterns during dominance and suppression of a given image, we may be able to use binocular rivalry as a window into the neuronal processes directly responsible for our capacity to be visually conscious of a given content (Crick, 1996).

This claim rests in part on the idea that dominance periods during rivalry can be valid surrogates of unconstrained conscious visual perception. An additional requirement is that it be legitimate to describe the suppressed phase as constituting a case of nonconscious perception of the stimulus, so that the contrast between both states can truly target neuronal processes endowed with some kind of specificity for consciousness.

These requirements appear to be met. On the one hand, subjects show normal performance in visual sensitivity for the detection of probes superimposed on the dominant figure, suggesting that conscious perception during this phase has not suffered major alteration (Blake \& Logothetis, 2002). On the other hand, suppression behaves as an energy filter that entails a drop in visual sensitivity to targets presented during these periods (Fukuda, 1981). Nevertheless, the suppressed pattern can be neurally processed to a certain extent, as indicated by the existence of visual adaptation effects, such as the tilt aftereffect, induced by the non-perceived image (Blake \& Fox, 1974; Dragoi, Sharma, \& Sur, 2000). Moreover, although changes in the suppressed stimulus can capture involuntary attention, voluntary attention cannot be directed to it (Blake, Yu, Lokey, \& Norman, 1998; Schall, Nawrot, Blake, \& Yu, 1993). This suggests that a certain degree of nonconscious perception can be attributed to the suppression phases.

\footnotetext{
${ }^{4}$ Ultimately, exclusivity depends on the contrast of both images. Very low contrast images can produce a fusion pattern that does not entail rivalry (Blake \& Logothetis, 2002).
} 
Although these considerations will be important in the interpretation of the results reviewed below, we wish to stress that our main aim is not to enter into the discussion of the specific neural processes that could distinguish conscious from nonconscious perception. Rather, our aim is to use binocular rivalry as a case study for examining aspects of the dynamics of ongoing experience. Our next step is to review briefly some neurobiological aspects of this phenomenon.

\subsection{Neurobiology}

Although binocular rivalry is an extensively studied phenomenon, its neurobiological mechanisms have not been fully explained. In a recent review, exponents of two dominant views came together to propose that binocular rivalry should be understood as arising from a combination of several mechanisms spanning lower and higher levels of brain function (Blake \& Logothetis, 2002; Wilson, 2003).

Numerous studies have addressed the nature of rivalry in the human as well as the monkey brain. Logothetis and collaborators have used single cell recordings in alert behaving monkeys and psychophysical experiments in humans to tackle this issue. They have found that when the two conflicting images are swapped between the eyes (thereby preventing one monocular channel from being continuously stimulated), rivalry is present and exhibits all the phenomenological and psychophysical characteristics for traditional viewing conditions (Logothetis, Leopold, \& Sheinberg, 1996). This finding suggests some kind of brain-scale mechanism is involved in solving the conflict rather than a competition between monocular channels. Work done by the same group, but in single cell recordings in awake behaving monkeys, has provided direct neurophysiological evidence of the different brain structures that may be involved in this phenomenon (Leopold \& Logothetis, 1996). It was reported that in V1 and V2 only $20 \%$ of the neurons followed the percept, despite full-fledged perceptual alternation. In contrast, as one moved "up" the processing pathway a higher percentage of neurons followed the percept (from 40\% in V4, MT, and MST to $90 \%$ in IT and STS).

In an fMRI study in humans, Tong, Nakayama, Vaughan, and Kanwisher (1998) showed that the neural activity correlated with perception during rivalry oscillated between the fusiform gyrus (when the subjects perceived a face) and the parahippocampal place area (when the subjects perceived a house). In another fMRI study, Lumer and coworkers provided evidence suggesting that distributed yet specific brain activation underlies the alternation (Lumer, Friston, \& Rees, 1998). Using a subtraction paradigm, they were able to show that spontaneous transitions among percepts were specifically associated with activation of right frontoparietal cortex, in contrast to stimulus driven alternations, which engaged mostly non-lateralized activity in visual cortex. Finally, following an idea of Diaz-Caneja from 1928, Kovacs and coworkers used two complementary patchwork patterns to induce rivalry (Kovacs et al., 1996). They observed that alternations were perceived between not only the actual presented patterns, but also and more interestingly between full reconstructed figures. It was as if prior to rivalry an interocular (higher level) grouping had taken place.

Yet not all studies favor such a "high level" or distributed brain activity hypothesis. Recently, rivalry related fluctuations of neural activity were detected as early as V1 (Polonsky, Blake, Braun, \& Heeger, 2000). The authors used a contrast tagging method, in which the difference in contrast between the two images allowed them to follow the corresponding signal by fMRI. At the same time, another study using the blind spot to generate rivalry has shown that interocular competition could resolve rivalry, thereby challenging the view of high-level processes as necessary to account for the alternation in perception (Tong \& Engel, 2001).

Whether it results from a low-level competition among monocular channels or a high-level brain-scale process, or a complex mixture of both (Wilson, 2003), binocular rivalry remains unexplained. What the experimental results do indicate, however, is that dominance periods in visual rivalry are related to brain patterns that comprise mainly visual areas, but also in some cases distributed brain activity that can include parietal and frontal cortices. These cortical regions have also been found to be active in a number of different experimental paradigms that address the neurobiological underpinnings of visual perception, working memory, and attention (Rees, Kreiman, \& Koch, 2002; Tong, 2003). While the precise location of such activity is an interesting issue in its own right, it will not be our main focus in the rest of this article.

On the basis of the aforementioned evidence, it is reasonable to suppose that, both at the neural level and in the general context of multistable perception, dominance periods in binocular rivalry can represent valid surrogates of unconstrained ongoing conscious perception. In Section 5 we present experimental work from our group 


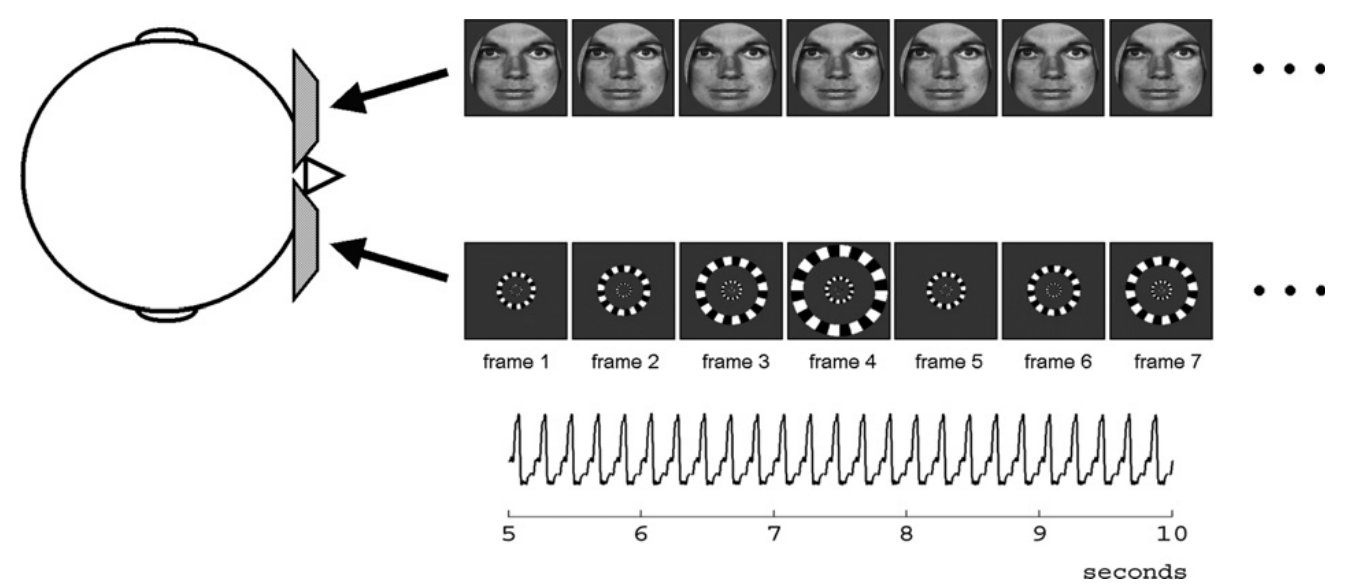

Fig. 3. Experimental setup for the binocular rivalry experiment: Subjects viewed through MEG-compatible polarized lenses the conflicting images presented with two different orthogonally polarized projectors as indicated in the top part of the figure. The face remained unchanged through the successive video frames of the first projector. In contrast the expanding checkerboard rings were constructed using different successive frames (see text for details). The lower panel presents $5 \mathrm{~s}$ of the time-course of a diode placed at the output of the second projector showing the $5 \mathrm{~Hz}$ frequency tag.

that aims to develop new concepts and analytical tools for studying the temporal flow of human experience using the binocular rivalry paradigm.

As described below, this work tested the hypothesis that during binocular rivalry cortical activity exhibits a dynamical structure corresponding to the phenomenal structure of the flow of conscious perception. In particular, it tested the prediction that brain activation for the flow of experience during rivalry can be identified without considering it as a two-state (perceive/no-perceive) system, but instead as one recurrent-variable metastable system, i.e., a system whose trajectory recurs in time without ever doing so in the same way.

\section{Methods}

The methodological framework we discuss in this section as well as the experimental results have been reported in detail in a series of recent articles (Cosmelli et al., 2004; David, Cosmelli, Hasboun, \& Garnero, 2003; David, Garnero, Cosmelli, \& Varela, 2002). Here we reproduce the most important aspects that are relevant to our project in this paper. ${ }^{5}$

\subsection{Experimental setup}

Te healthy voluntary subjects (nine men, two women) participated in the original binocular rivalry experiment (Cosmelli et al., 2004). Of these, seven subjects (six men, one woman; mean age 29.8 yrs) were retained for further MEG recordings while presented with the rival stimulation. Neuromagnetic recordings were done in a 151-SQUID sensor CTF MEG (CTF System Inc., Port Coquitlam, BC, Canada) in the MEG Centre, Hôpital de la Salpêtrière, Paris, France. The experimental protocol was approved by the Hôpital de la Salpêtrière ethics committee (CCPPRB). Subjects were exposed to two viewing conditions: a black screen (resting condition) and a rival viewing condition. Rival viewing was obtained by projecting polarized non-fusible images onto a screen situated $85 \mathrm{~cm}$ in front of the subject. To separate both images, subjects used polarized MEG-compatible lenses. During rival viewing one eye saw a series of expanding black and white checkerboard rings while the other eye saw a black and white feminine face of emotionally neutral expression (Fig. 3). Stimuli were viewed foveally through a circular aperture of $4^{\circ}$ radius. Subjects were instructed to maintain fixation on a dim spot at the center of the aperture. For each subject luminance was adjusted for each stimulus independently until a full and comfortable perceptual oscillation was achieved, as indicated by his/her verbal

\footnotetext{
${ }^{5}$ Figs. 3-7and text excerpts reproduced from Cosmelli et al. (2004) with permission by Elsevier.
} 
report. The face was projected into the dominant eye to favor a good suppression of the expanding rings. Subjects reported smooth and consistent transitions from one image to the other and clear dominance/suppression periods. They were instructed to indicate by pressing one of two buttons when full dominance of each image was achieved. Subjects were instructed not to indicate mixed periods of dominance. Each viewing condition lasted two minutes and was followed by a pause of $40 \mathrm{~s}$. MEG signals were acquired continuously at $1250 \mathrm{~Hz}$ and band passed between 0 and $200 \mathrm{~Hz}$, and horizontal and vertical electro-oculogram (EOG) was recorded in parallel (for further details regarding the experimental setup and behavioral results see Cosmelli et al., 2004).

\subsection{Frequency tagging}

In this experimental setting we used a frequency tagging approach (Brown \& Norcia, 1997; Cobb, Morton, \& Ettlinger, 1967; Lansing, 1964; Tononi, Srinivasan, Russell, \& Edelman, 1998). The principle of this approach consists in using an intrinsic frequency in a given stimulus that can be followed in the subsequent evoked brain response. In our experiment, the expanding checkerboard rings extended radially from $0^{\circ}$ to $4^{\circ}$ of visual eccentricity, as in an optical flow. Because of the retinotopic organization along the calcarine and primary visual cortex, the expanding checkerboard rings will produce a concomitant posterior-anterior wave of activation. The spanning velocity can thus be used as a frequency tag (Wandell, 1999), which in our experiment was fixed at $5 \mathrm{~Hz}$ (see Fig. 3).

\subsection{Descriptive and intersubjective invariants}

All subjects participating in this study were extensively trained prior to actual MEG recording, totaling a minimum of $2 \mathrm{~h}$ of perceptual rivalry viewing per subject. During this training period we asked the subjects to freely describe the experience as they were engaged in it. All descriptions were recorded and transcribed for further analysis.

The main objective of asking for the subjects' descriptions was to explore the possibility that a first-person characterization of the subjective experience could help guide the analysis of the neurophysiological data. The approach we used was guided by the methodological framework of neurophenomenology (Lutz \& Thompson, 2003; Varela, 1996). The aim is to produce descriptive phenomenal invariants of the experience as it is lived in the first-person by the individual subject. These descriptive invariants can then be contrasted across subjects in order to obtain intersubjective invariants that can guide or constrain the collection and analysis of the neurophysiological data.

In this experiment, we explored two intersubjective invariants that emerged from the first-person descriptions. Given the preliminary nature of the implementation of this approach, we chose to restrict ourselves to very coarse-grained invariants that we could confidently say would hold for the experimental group. Every subject undergoing the experience described recurring periods of dominance of the checkerboard rings alternating with recurring dominance periods of the face. Yet they had difficulty in pinpointing stable forms of transition between both images and usually described them as extremely variable in their timing and in the way in which they developed. ${ }^{6}$ Of course, this description might seem almost trivial to anyone who has experienced rivalry with stimuli that extend more than one degree of visual field. Yet beneath the apparent triviality lies a crucially important fact, namely, that the experience of binocular rivalry is both recurrent and variable. Recurrence and variability are two strong intersubjective invariants of experience that hold for most naïve observers. ${ }^{7}$ Although obvious, these invariants have not been considered previously in binocular rivalry experiments in the way we have done here, namely, as significant constraints on the detection and interpretation of the underlying neural activity. If we wish to study the brain patterns that underlie binocular rivalry in time,

\footnotetext{
${ }^{6}$ For example, sometimes the transition from face to rings was reported to start at the center of the face and expand outwards rapidly; at other times it began on the side of the face and slowly invaded the rest of it in a wave-like fashion; at other times it appeared as a destabilization of the entire face that was then submerged by the rings that appeared from the background as a coherent whole, and so on.

${ }^{7}$ Whether highly trained subjects can hold one image indefinitely is an unresolved issue (Blake \& Logothetis, 2002; Carter et al., 2005).
} 
then we have to allow for at least these two aspects of the experience. As the following section explains, we used a framework that explicitly takes these dynamic aspects into consideration.

\subsection{An analytical framework adapted to the experience}

Given that an important part of our objective in this paper is to explore methodological developments relevant to the study of the dynamics of ongoing experience, we need to present in some detail the methods used in our binocular rivalry experiment. These methods comprised three main steps-scalp analysis, cortical source analysis through MEG inverse problem estimation, and dynamical analysis of the estimated cortical time-courses. We now summarize these three steps.

\subsubsection{Scalp data analysis}

To determine the presence of the frequency tag during the binocular rivalry experience continuous segments of scalp data filtered between 1 and $45 \mathrm{~Hz}$ were analyzed using a fast Fourier transform (FFT) (MATLAB 6.5, The MathWorks, Inc.). To evaluate the specificity of the frequency tag for conscious perception periods of the expanding checkerboard rings during rivalry we then followed the evolution of the $5 \mathrm{~Hz}$ tag amplitude in time. To this end we first selected the MEG scalp sensor with the best sensitivity to the $5 \mathrm{~Hz}$ tag for each subject. It was defined as the sensor showing the highest ratio of $5 \mathrm{~Hz}$ peak amplitude of the power spectra to the average amplitude around it in the 3-7 Hz band. We then evaluated the average amplitude of the selected sensors in a $500 \mathrm{~ms}$ time window centered on the button presses signaling full perceptual dominance of the rings and of the face, for each subject individually, and across subjects.
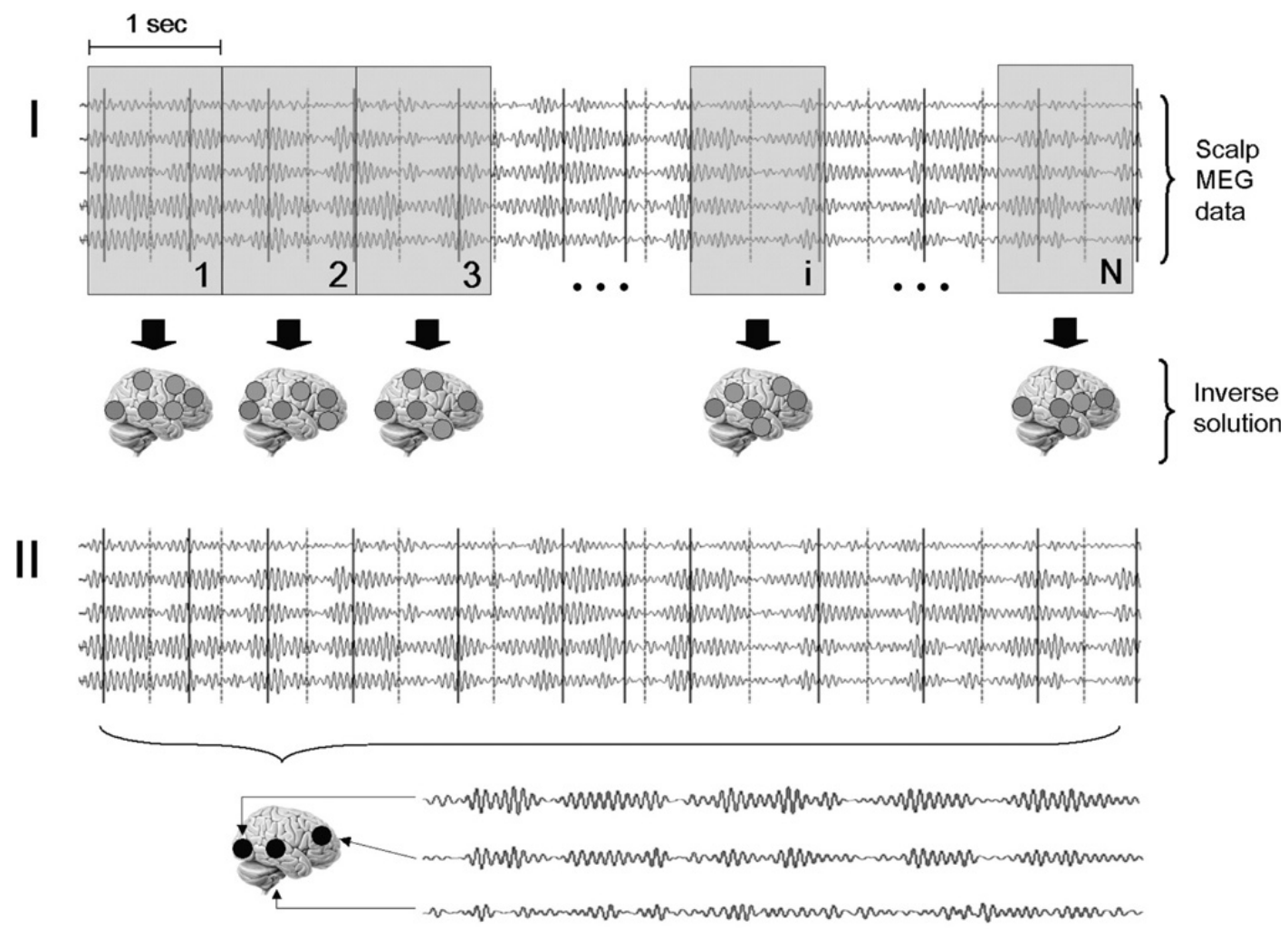

Recurrent cortical sources across $\mathrm{N}$ cortical time-courses segments

Fig. 4. Schematic presentation of the methodological approach followed in this study. (I) Continuous scalp MEG data of either viewing condition is segmented into one second successive epochs $(1,2,3, \ldots, i, \ldots, N)$. Broken and unbroken vertical lines indicate dominance of face and rings respectively. Each epoch is subject to the inverse estimation of cortical sources using a focal solution of a distributed model. (II) Only those sources that recur significantly throughout the $\mathrm{N}$ epochs (as compared to surrogate data) are kept and used to adjust the entire scalp viewing period. The cortical time-courses are then used for further dynamical analysis. 


\subsubsection{MEG estimation of cortical activity}

The inverse problem approach used in this study is composed of two main steps (see Fig. 4 for a schematic presentation of this part of the analysis). Data was filtered between 3 and $7 \mathrm{~Hz}$ prior to inverse estimation. Successive 1 second epochs of continuous scalp data, for each viewing condition, are considered individually and the corresponding active cortical source space for each epoch is estimated using a focalization of a cortically distributed inverse solution (David et al., 2002). A unique source space is defined as the ensemble of sources that show significant recurrence across the successive epochs (David et al., 2003). A null distribution of source recurrence is constructed using surrogate data as described in detail elsewhere (David et al., 2003). The unique source space is then used to compute the time course of the entire data segment using a minimum norm source estimate (Dale \& Sereno, 1993; Hamalainen, Hari, Llmoniemi, Knuutila, \& Lounasmaa, 1993). In order to obtain realistic extensions of locally coherent brain activity (Nunez \& Silberstein, 2000) and to regroup clusters of correlated sources we apply an expansion algorithm using the recurrent source space as seeds (David \& Garnero, 2002). We thus explain the scalp energy of the steady state condition (the ongoing perceptual alternation or the ongoing resting state) by a source space composed of those brain sources that are detected recurrently with no restrictions on the temporal sequence of their activation. This approach explicitly takes into consideration the variable dynamics of the perceptual transitions in binocular rivalry and avoids any averaging procedure. Sources are then labeled according to standard morphological landmarks (Duvernoy, 1999).

\subsubsection{Dynamical analysis}

As a measure of dynamical interaction among sources oscillating in the same frequency band we quantified phase-locking between reconstructed brain signals (Lachaux, Rodriguez, Martinerie, \& Varela, 1999; Le Van Quyen et al., 2001; Tass et al., 1998). Using the wavelet-based approach described in Lachaux et al. $(1999,2002)$, it is possible to obtain an index of phase synchrony $\rho$ that quantifies the dispersion of the difference of instantaneous phases between two filtered signals during a given temporal extension. This value was computed every $50 \mathrm{~ms}$ for each cortical source pair on a sliding time window ( $1 \mathrm{~s}$ duration, i.e. 5 oscillations at $5 \mathrm{~Hz}$ ). $\rho$ values are comprised between 0 and 1, and increase with the strength of the phase locking.

Given the descriptive invariants introduced above, we are interested in synchronous activity that shows recurrence throughout the viewing period without necessarily being time-locked to a particular event. Furthermore, because we are interested in studying the phenomenon as it deploys in time we wish to avoid averaging of (supposedly) independent trials. We have therefore proceeded in the following way, taking into account the temporal extension of the signals. We define a first threshold $\left(\mathrm{th}_{1}\right)$ for a $p<0.01$ by generating $K=99$ surrogate $\rho\left(\rho^{\mathrm{s}}\right)$ time courses from independent Gaussian noises with the same length and filtering as the original signal: $\operatorname{th}_{1}=\max \left[\rho_{1}^{\mathrm{s}} \ldots \rho_{K}^{\mathrm{s}}\right]$. We choose a demanding $p<0.01$ threshold at this point because the hypothesis test is relatively weak. Over these $K$ realizations, the maximum percentage of time that surrogate $\rho^{\mathrm{s}}$ reaches $\mathrm{th}_{1}$ defines a temporal threshold $\left(\mathrm{th}_{2}\right)$. If the synchrony value of a given pair of brain signals is above th longer than $t_{2}$, it is considered significant. After determining the specificity of the evoked activity at the frequency tag, for the perceptual dominance periods (see Fig. 5), and to reveal the cortical evoked synchronous networks that correlate with the perceptual dominance of the expanding rings, we calculated the normalized cross-correlation (CC) at lag $=0$ between all $\rho$ time-courses and the $5 \mathrm{~Hz}$ envelope of the MEG scalp sensor with the best tag sensitivity. $\mathrm{CC}$ was then thresholded for each source pair at a value of $\mathrm{CC}^{\mathrm{s}}$ which was determined using surrogate data of type FT1 (Palus \& Hoyer, 1998). ${ }^{8}$ We set the threshold to $p<0.05$ by generating 19 FT1 surrogate $\rho^{\mathrm{s}}$ time-courses for each possible source pair and estimating the $\mathrm{CC}^{\mathrm{s}}$ with the corresponding $5 \mathrm{~Hz}$ envelope. Only those $\rho$ time-courses with higher $\mathrm{CC}$ to the $5 \mathrm{~Hz}$ envelope than the maximum of their surrogate distribution are considered.

In summary, if a given source pair is synchronous for a certain total amount of time during the entire viewing period, it will be considered significant, regardless when this happens. Here again we seek to apply the constraint imposed by the descriptive invariants to the actual analysis of the data.

\footnotetext{
${ }^{8}$ These surrogate data realize the null hypothesis of two linear stochastic processes asynchronously oscillating with the same frequencies (power spectra) as the original time series under study.
} 

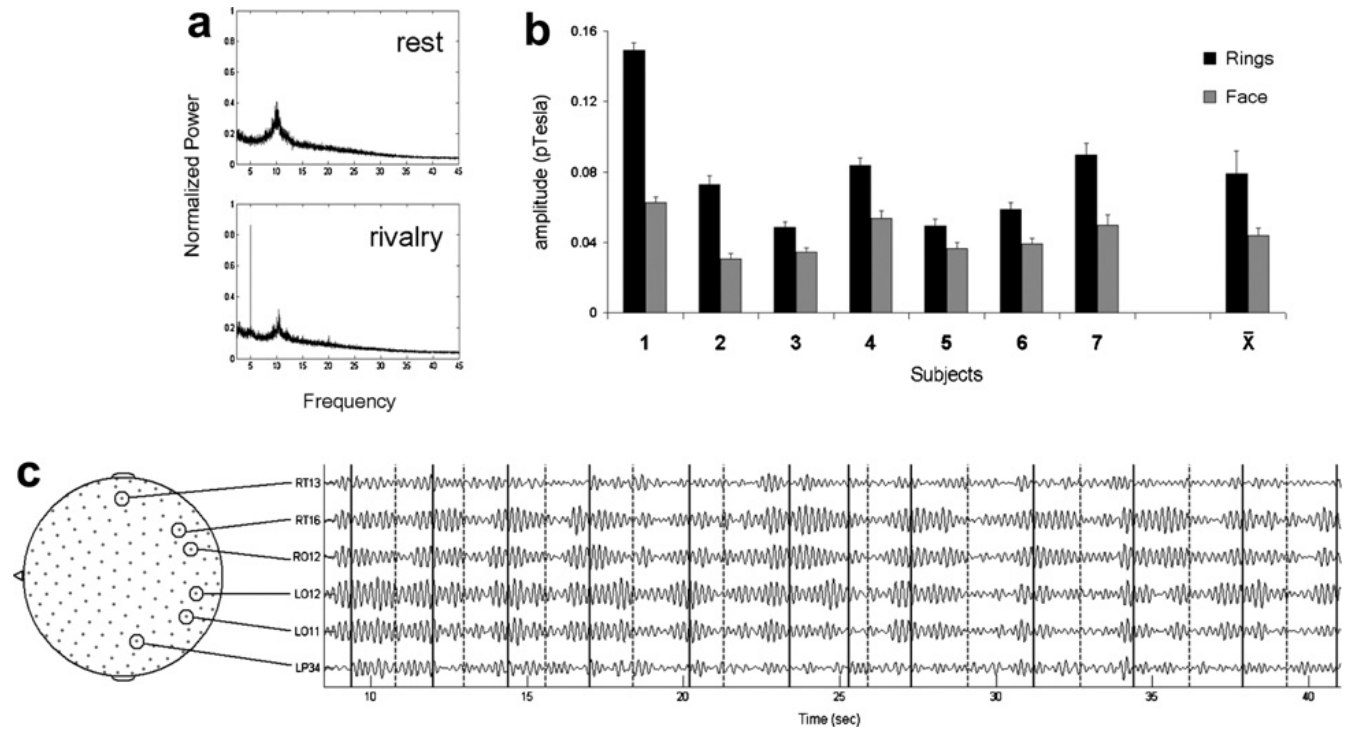

Fig. 5. Specificity of the frequency tag for perceptual state: (a) Average overall scalp spectra for both resting and rival viewing conditions showing the sharp peak at $5 \mathrm{~Hz}$. Frequency is plotted against normalized power. (b) Mean amplitude during rings (filled bars) and face (gray bars) perception, of the MEG sensor with the best sensitivity to the tag, for each subject (S1-S7), and across subjects (X). Error bars indicate one standard error of the mean $(S E M)$. (c) Time course of six MEG sensors filtered in the 3-7 Hz band for S1. Position of the sensors are indicated on the left diagram. Dotted lines indicate subject's answer to face perception; continuous lines indicate expanding rings perception.

\section{Results}

There are three main results of this work we wish to present in view of the central concern of this paper. We will first show that the frequency tag can follow under non-averaged conditions the evolution of the dominance periods of the rings on the scalp data. This result is in agreement with previous works by Lansing (1964) and Brown and Norcia (1997). We will then be concerned with the evolution of the cortical network of evoked activity during a rival viewing period as estimated using the inverse problem approach presented above. Finally, we will present the dynamics of the modulation of the frequency-tag amplitude both at the scalp and at the cortical level for an average dominance period. This last point is of particular significance in light of the phenomenological framework introduced earlier. (We will not discuss the precise localization results in detail or the individual distribution of the cortical evoked synchronous networks for each subject. The interested reader is referred to the original report for these questions.)

\subsection{Scalp specificity of the frequency tag}

We first studied the amplitude time series of the $5 \mathrm{~Hz}$ tag to evaluate its specificity to conscious perception of the expanding checkerboard rings during rivalry. As described above, we selected the MEG scalp sensor with the best sensitivity to the $5 \mathrm{~Hz}$ tag as the sensor showing the highest ratio of $5 \mathrm{~Hz}$ peak amplitude of the power spectra to the average amplitude around it, in the 3-7 Hz band. For the seven subjects (S1-S7) ratios were S1: 34.1; S2: 14.9; S3: 16.1; S4: 14.7; S5: 14.1; S6: 9.0; S7: 22.9; mean =17.97, and the selected sensors were consistently occipital. Average amplitude of the selected sensors upon rings and face dominance is presented in Fig. 5b for each subject and across subjects. All subjects presented higher amplitude during ring perception than during face perception (Mann-Whitney U-test for independent samples: $p<0.025$ ). The mean difference across subjects was also significant (Wilcoxon test for paired samples: $p<0.025)$. Nevertheless, the difference in the ratios presented above and the average amplitudes seen in Fig. 5b suggest a differential sensitivity to the frequency tag among subjects. Fig. 5c shows the ongoing modulation of the frequency tag for one subject during binocular rivalry. It can be seen that the ongoing, non-averaged modulation of the frequency tag already shows a strong correlation to the subject's response 
to the perceptual dominance of expanding rings. These results are in accordance with previous work (Brown \& Norcia, 1997; Cobb et al., 1967; Lansing, 1964; Tononi et al., 1998) showing that during binocular rivalry the evoked brain response to a frequency tag is consistently modulated throughout perceptual alternations.

\subsection{Cortical dynamics during rivalry}

The specificity of the frequency tag suggests that by estimating the brain sources in the 3-7 $\mathrm{Hz}$ band it should be possible to reveal an important part of the cortical dynamics specific to the perceptual dominance periods. The results of the MEG inverse estimation showed that throughout the entire viewing period activity was evoked at the tag's frequency throughout several distinct brain regions. Most of the energy was concentrated in the medial occipital cortex as well as the lateral occipito-temporal junction (putative MT). Additionally, bilateral superior parietal, temporal pole, and several frontal regions including posterior parts of the left superior and inferior frontal gyri, bilateral anterior cingulate cortex and adjacent medial aspect of the superior frontal gyrus, and orbitofrontal cortex were detected (Cosmelli et al., 2004).

To analyze the spatio-temporal dynamics of the specific cortical networks evoked by the tagged stimulus during conscious perception we then followed the ongoing pattern of synchronous brain activity throughout a series of perceptual transitions. Fig. 6 shows this evolution for one subject (S2). It is possible to see how the average cortical synchrony in the tag's frequency band follows tightly the perceptual alternation throughout the rival viewing. When a series of individual dominance periods are analyzed, a dynamical buildup of the evoked synchronous brain network is apparent. At the beginning of each transition very few synchronous

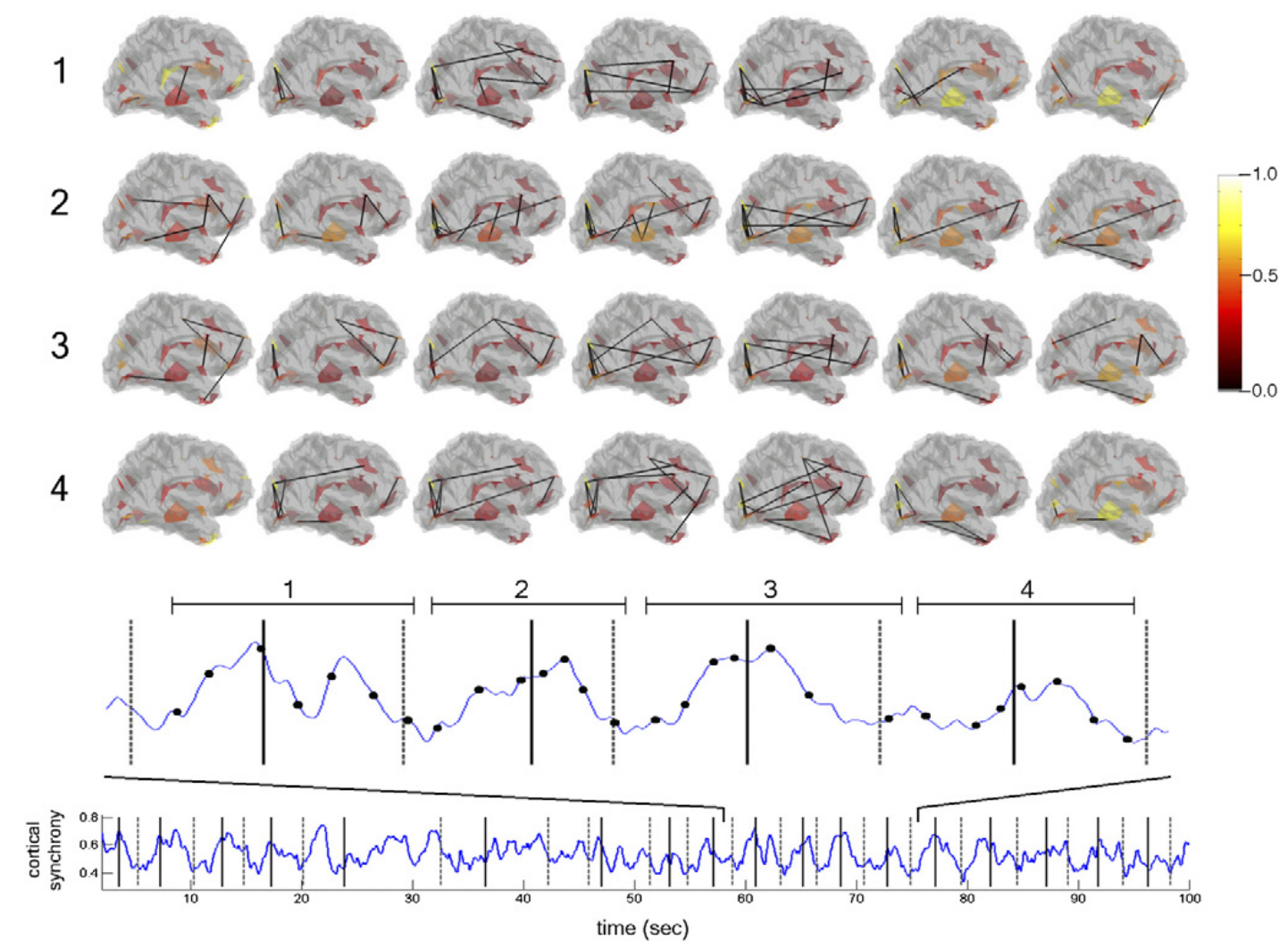

Fig. 6. Dynamic cortical patterns during conscious perception in binocular rivalry: the figure shows a series of four perceptual moments (labeled 1 through 4) during binocular rivalry in subject 2. The upper part of the figure shows the sagittal view of the evolving cortical network in successive snapshots. Color codes for sources' energy (normalized to the maximum) according to the color scale on the left. Black lines link brain regions among which synchrony, in the 3-7 Hz band, reaches significance at the moments indicated by the black dots on the blue curve just below. The latter is a detail of the time-course of average synchrony shown in the lower. Vertical black continuous and gray dotted lines are the subject's indication of full perceptual dominance of the expanding rings and the face, respectively. (For interpretation of the references to color in this figure legend, the reader is referred to the web version of this paper.) 
pairs are evident (first column of snapshots). As dominance develops, the occipital pole shows an increase in local synchrony involving primary visual cortex and more dorsal occipital areas. Long-range synchronous activation is then established between the occipital regions and more frontal areas, including mainly medial frontal regions. This pattern of occipito-frontal co-activation is maintained for several moments (1-2 s) and coincides with the full dominance of the tagged expanding checkerboard rings. As suppression begins, long-range synchronous activation falls apart leaving coactive areas in the occipital pole, and in some cases, infero-temporal regions up to the temporal pole. During full suppression very few synchronous regions are left and brain patterns return to the pre-transition situation.

\subsection{Average modulation of cortical dynamics}

It has been extensively argued that perceptual integration may rely on a coordinated network of temporally coherent brain activity (Edelman \& Tononi, 2000; Engel, Fries, Konig, Brecht, \& Singer, 1999; Engel \& Singer, 2001; Rodriguez et al., 1999; Singer et al., 1997; Varela, Lachaux, Rodriguez, \& Martinerie, 2001). Accordingly, the estimation of the cortical sources suggested that the modulation of brain activity during perceptual dominance may implicate distributed brain regions. It was therefore expected that during conscious perception of the $5 \mathrm{~Hz}$ rings, synchronous activation among cortical sources in this frequency band would rise and fall in concert with perceptual dominance. Fig. 7 shows the time-course of significant phase synchronous activity between brain sources (see Section 5.4.3 for definition) centered on the response for ring perception, averaged across subjects and dominance periods. A consistent correlation between the time course of the synchronization of the cortical network and alternations in conscious perception is evident. As expected, the timecourse of the evoked synchronous activation tightly correlates with the envelope of the $5 \mathrm{~Hz}$ scalp response. Thus the frequency tag revealed a specific co-activated cortical network that was endogenously modulated throughout the successive waves of conscious perception during binocular rivalry in the form of a distinct bellor mountain/valley-type pattern.

\section{Discussion}

An extensive discussion of the technical points regarding the experimental work presented here can be found in the original article (Cosmelli et al., 2004). Here we wish to discuss some specific points relevant to

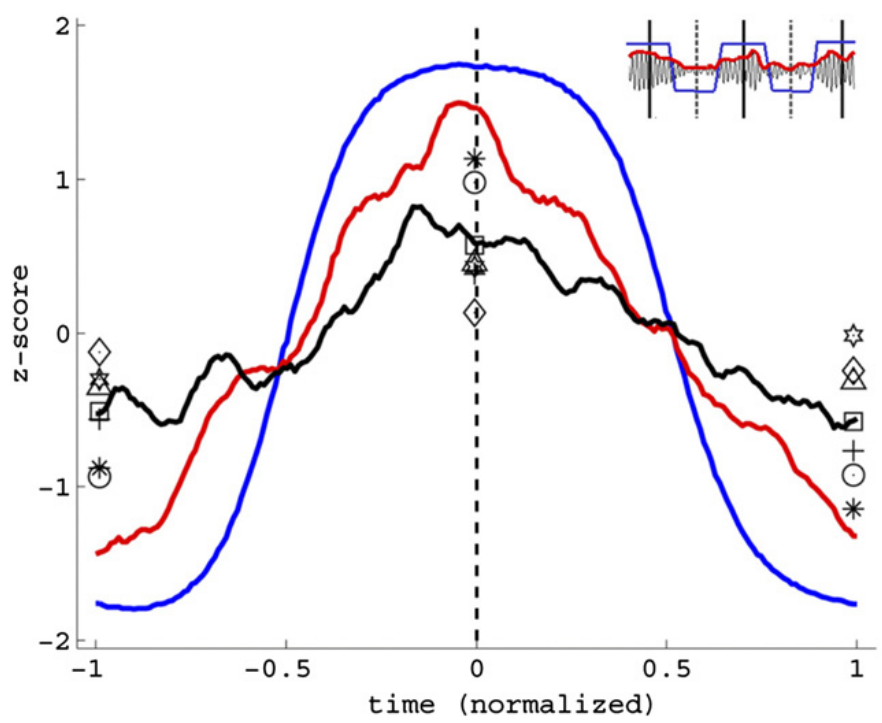

Fig. 7. Modulation of brain activity and conscious perception: Average around the answer $(t=0)$ indicating full dominance of the expanding checkerboard rings of the response function (blue line), scalp sensor with the best tag sensitivity $5 \mathrm{~Hz}$ envelope (red line) and mean cortical synchrony (black line) over all seven subjects. Inset shows detail on the construction of the response function and $5 \mathrm{~Hz}$ envelope. Average z-score values are shown. Individual values for synchrony are indicated by the different symbols lined onto the subjects' indication for face perception and onto $t=0$. Time is normalized respect to the previous $(-1)$ and subsequent $(+1)$ indication of face dominance in order to represent varying dominance/suppression periods that occur across subject in a common (relative) temporal frame. 
neurodynamical approaches that view consciousness as an ongoing process having its own phenomenal temporality and dynamics (Cosmelli et al., 2007).

\subsection{Binocular rivalry, consciousness, and metastability}

In this work we have made use of rather minimal descriptive phenomenal invariants and intersubjective invariants of the experience of binocular rivalry-perception recurrently and spontaneously alternates, exhibiting variable dynamics of transition. Nevertheless, these invariants have not previously been taken into consideration in assessing the underlying neural processes. On the contrary, binocular rivalry is usually viewed as composed of contrasting and clear-cut conscious and nonconscious states (Crick, 1996). The temporal and intrinsically metastable dynamics of the rivalry experience is rarely considered as a basic and ineliminable feature (but see Kelso, 1995). Yet if we actually attend to the descriptive phenomenal invariants of the experience, we are immediately confronted with the dynamic alternation as a fundamental structure, and not with two stable and independent perceptual experiences clearly differentiated one after the other (see also Noe \& Thompson, 2004).

By explicitly constraining the analytical methods through this invariant of the experience of rivalry, we have been able to describe ongoing patterns of neural activity that are modulated in concert with the perceptual dominance of a target stimulus. Importantly, the cortical distribution of the network of evoked brain activity during the dominance of the frequency tagged stimulus can be considered as a test and eventually a validation of the framework proposed here.

In other studies, it has been shown that non-rival visual presentation of a stimulus analogous to the expanding checkerboard rings used in our study is correlated with the strong activation of striate and extrastriate visual cortex, including bilateral V1/V2 and more dorsal regions including MT in the lateral occipito-temporal junction (Tootell et al., 1995, 1997; Wandell, 1999). These areas were consistently detected by our approach and showed robust activity throughout the dominance periods (see Table 1 in Cosmelli et al., 2004). Furthermore, we also detected activation in bilateral anterior cingulate and medial frontal cortex (anterior cingulate cortex), as well as right superior parietal gyrus. Using fMRI, Lumer et al. (1998) found strong activation of the medial frontal region during rivalry. Likewise, they showed that right prefrontal cortex was specifically engaged during spontaneous transitions of perceptual dominance. In a subsequent study, Lumer and Rees (1999) presented evidence of co-variation of parietal and lateral frontal regions in a similar paradigm.

The convergence of these results (see also Section 4.2 above) with those obtained through our approach suggests that the framework proposed here is well suited to capture an important part of the brain dynamics during ongoing conscious experience, as exemplified in the restricted case of binocular rivalry. A central and novel feature of our framework is that provides a statisical instantiation for the phenomenal invariants of recurrence and variability. Using this method, it becomes possible to reveal cortical dynamics without any averaging procedures that would destroy precisely the variable aspects that are arguably constitutive of the phenomenon. In this way, we can describe the distributed neural activity as constituting a metastable regime - as a continuous process of tendencies toward regions of relative stability (during dominance phases) through changing trajectories (Friston, 2000; Kelso, 1995; Thompson \& Varela, 2001).

It is interesting to note that the bell-type form of the dominance periods during binocular rivalry (Figs. 6 and 7) is reminiscent of William James's prediction of the form brain activity would take for any given conscious moment (James, 1981). The main idea is that conscious experience and the underlying brain processes do not occur in a clear-cut step-wise fashion, but rather develop dynamically from a previous non-neutral state, are sustained and then subside, only to give rise to the next moment. In accord with James's intuition, several authors have stressed the transient pulsating nature of neural dynamics (Freeman, 1999; Friston, 2000; Kelso, 1995; Varela, 1999) as a way of accounting for the streaming momentariness of consciousness (VanRullen \& Koch, 2003).

\subsection{Toward the study of the flow of experience}

We thus return to our guiding theme of the standing-streaming character of conscious experience. As discussed in Section 2, the experience of both a standing now and a streaming flow constitute an indissociable 
phenomenal structure of consciousness. We have argued that neuroscience can begin to study this structure, but that to do so we need to develop methods that take these features of momentariness and flow as a guide to defining meaningful observations and measurements of brain dynamics. As a first step, tracking the two (coarse-grained) invariants of recurrence and variability enables us to capture both the stability of the dynamic process and simultaneously its temporal singularities.

We are certainly not the first ones to argue for the importance of taking the uniqueness of mental events from moment to moment as a basic constraint in the choice of analytical tools in cognitive neuroscience (see Frith, 2002; Jack \& Roepstorff, 2002). A growing number of neuroscientists have argued for the need for single-trial approaches that take into account not only the invariant aspects of each individual event, but also their ineliminable variability. Single-trial analyses have been developed in several domains of cognitive neuroscience, such as the study of phase-relations between brain signals (Hurtado, Rubchinsky, \& Sigvardt, 2004; Lachaux et al., 2000, 2002), the estimation of underlying brain sources from scalp EEG/MEG recordings (David \& Garnero, 2002; David et al., 2002, 2003; Ioannides, 2001; Ioannides et al., 1995; Jensen \& Vanni, 2002), evoked potential analysis and classification (Jung et al., 2001; Laskaris \& Ioannides, 2001; Makeig et al., 2002) and the analysis of event-related BOLD responses (Bingel et al., 2004; Burke, Murphy, Garavan, \& Reilly, 2004; Duann et al., 2002; Lloyd, 2002). In the case of complex dynamical systems-of which the nervous system is probably the most paradigmatic example (Friston, 2000) - this methodological constraint seems a basic requirement. Complex dynamical systems can present recurrent trajectories while always following a slightly different (variable) path, and must therefore be described accordingly (Cosmelli et al., 2007; Faure \& Korn, 2001; Huang et al., 1998; Korn \& Faure, 2003).

In this paper we have proposed an electrophysiological approach that seeks to operationalize the notions of recurrence and variability in the analysis of brain data from subjects experiencing multistable perception. In closing, we wish to call attention to an important qualification. In the experiment described above, a frequency-tag approach was used in order to facilitate the estimation of neural activity. In this way, the signal-to-noise ratio is enhanced and the target process is marked for further analysis, thereby providing an ideal situation in which to test the validity of the strategy. Yet this frequency-tag approach might not be so easy to implement when dealing with unrestricted, ongoing experience. For example, how could one tag a thought?

It is possible, however, to think of an approach to this problem in the domain of visual experience. One of the most typical activities human beings perform is free visual scanning of the immediate and surrounding environment. It is easy to see that, by selectively tagging different objects in a visual display on a computer screen, one could make use of the framework proposed here in order to study the neural processes that underlie ongoing perceptual selection. Indeed, work by Hillyard, Muller, Morgan, and collaborators suggest that it is possible to follow the time-course of attentional facilitation by using a frequency-tag approach (Morgan, Hansen, \& Hillyard, 1996; Muller, Teder-Salejarvi, \& Hillyard, 1998; Muller et al., 1998).

In any case, the invariants of recurrence and variability apply not only to multistable perception, but also are constitutive of conscious experience in general. Most of our daily experience is that of already known (recurrent) objects of consciousness or states of mind that follow one another in new and always changing (variable) ways. This basic fact strongly supports the plausibility of the framework proposed here as a first step in developing a general strategy to investigate the flow of human experience.

\section{Acknowledgment}

DC acknowledges postdoctoral support by the McDonnell Project in Philosophy and the Neurosciences and funding from the PBCT-CONICYT ACT-45, Chile. ET acknowledges the support of the McDonnell Project in Philosophy and the Neurosciences and the Social Science and Humanities Research Council of Canada for support through a Canada Research Chair (2002-2005).

\section{References}

Alais, D., \& Blake, R. (1999). Grouping visual features during binocular rivalry. Vision Research, 39, 4341-4353.

Bingel, U., Lorenz, J., Glauche, V., Knab, R., Glascher, J., Weiller, C., et al. (2004). Somatotopic organization of human somatosensory cortices for pain: A single trial fMRI study. NeuroImage, 23(1), 224-232. 
Blake, R. (1989). A neural theory of binocular rivalry. Psychological Review, 96(1), 145-167.

Blake, R., \& Fox, R. (1974). Adaptation to invisible gratings and the site of binocular rivalry suppression. Nature, 249(456), 488-490.

Blake, R., \& Logothetis, N. K. (2002). Visual competition. Nature Reviews Neuroscience, 3, 1-11.

Blake, R., Yu, K., Lokey, M., \& Norman, H. (1998). Binocular rivalry and visual motion. Journal of Cognitive Neuroscience, 10, 46-60. Breese, B. B. (1909). Binocular rivalry. Psychological Review, 16, 410-415.

Brown, R. J., \& Norcia, A. M. (1997). A method for investigating binocular rivalry in real-time with the steady-state VEP. Vision Research, 37(170), 2401-2408.

Burke, D., Murphy, K., Garavan, H., \& Reilly, R. (2004). Pattern recognition approach to the detection of single-trial event-related functional magnetic resonance images. Medical \& Biological Engineering \& Computing, 42(5), 604-609.

Carter, O. L., Presti, D. E., Callistemon, C., Ungerer, Y., Liu, G. B., \& Pettigrew, J. (2005). Meditation alters perceptual rivalry in Tibetan Buddhist monks. Current Biology, 15(11), R412-R413.

Cobb, W. A., Morton, H. B., \& Ettlinger, G. (1967). Cerebral potentials evoked by pattern reversal and their suppression in visual rivalry. Nature, 216, 1123-1125.

Cosmelli, D., David, O., Lachaux, J. P., Martinerie, J., Garnero, L., Renault, B., et al. (2004). Waves of consciousness: Ongoing cortical patterns during binocular rivalry. NeuroImage, 23(1), 128-140.

Cosmelli, D., Lachaux, J.-P., \& Thompson, E. (2007). Neurodynamical approaches to consciousness. In P. D. Zelazo, M. Moscovitch, \& E. Thompson (Eds.), The Cambridge handbook of consciousness. New York: Cambridge University Press.

Crick, F. (1996). Visual perception: Rivalry and consciousness. Nature, 379, 485-486.

Dale, A. M., \& Sereno, M. I. (1993). Improved localization of cortical activity by combining EEG and MEG with MRI cortical surface reconstruction: A linear approach. Journal of Cognitive Neuroscience, 5(2), 162-176.

David, O., Cosmelli, D., Hasboun, D., \& Garnero, L. (2003). A multitrial analysis for revealing significant corticocortical networks in magnetoencephalography and electroencephalography. NeuroImage, 20, 186-201.

David, O., \& Garnero, L. (2002). Time-coherent expansion of MEG/EEG cortical sources. NeuroImage, 17, $1277-1289$.

David, O., Garnero, L., Cosmelli, D., \& Varela, F. J. (2002). Estimation of neural dynamics from MEG/EEG cortical current density maps: Application to the reconstruction of large-scale cortical synchrony. IEEE Transactions in Biomedical Engineering, 49(9), 975-987.

Ditzinger, T., \& Haken, H. (1989). Oscillations in the perception of ambiguous patterns. Biological Cybernetics, 61, $279-287$.

Dragoi, V., Sharma, J., \& Sur, M. (2000). Adaptation-induced plasticity of orientation tuning in adult visual cortex. Neuron, 28(1), 287-298.

Duann, J. R., Jung, T. P., Kuo, W. J., Yeh, T. C., Makeig, S., Hsieh, J. C., et al. (2002). Single-trial variability in event-related BOLD signals. NeuroImage, 15(4), 823-835.

Duvernoy, H. M. (1999). The human brain: Surface, three-dimensional sectional anatomy with MRI, and blood supply (2nd ed.). New York: Springer.

Edelman, G. M., \& Tononi, G. (2000). A universe of consciousness. Basic Books.

Engel, A. K., Fries, P., Konig, P., Brecht, M., \& Singer, W. (1999). Temporal binding, binocular rivalry, and consciousness. Consciousness and Cognition, 8(2), 128-151.

Engel, A. K., \& Singer, W. (2001). Temporal binding and the neural correlates of sensory awareness. Trends in Cognitive Sciences, 5(1), $16-25$.

Faure, P., \& Korn, H. (2001). Is there chaos in the brain? I. Concepts of nonlinear dynamics and methods of investigation. Comptes Rendus de l Academie des Sciences Serie III, 324(9), 773-793.

Freeman, W. J. (1999). How brains make up their minds. Phoenix.

Friston, K. J. (2000). The labile brain. I. Neuronal transients and nonlinear coupling. Philosophical Transactions of the Royal Society of London Series B, 355, 215-236.

Frith, C. (2002). How can we share experiences? Comment from Chris Frith. Trends in Cognitive Sciences, 6(9), 374.

Fukuda, H. (1981). Magnitude of suppression of binocular rivalry within the invisible pattern. Perceptual and Motor Skills, 53, 371-375.

Gallagher, S. (1998). The inordinance of time. Evanston, Illinois: Northwestern University Press.

Hamalainen, M., Hari, R., Llmoniemi, R. J., Knuutila, J., \& Lounasmaa, O. V. (1993). Magnetoencephalography-theory, instrumentation, and applications to noninvasive studies of the working human brain. Reviews of Modern Physics, 65(2), 413-498.

Hanna, R., \& Thompson, E. (2003). The spontaneity of consciousness. In E. Thompson (Ed.), New essays in phenomenological philosophy of mind. Canadian Journal of Philosophy, Supplementary Vol. 29, pp. 133-162.

Huang, N. E., Shen, Z., Long, S. R., Wu, M. C., Shih, H. H., Zheng, Q., et al. (1998). The empirical mode decomposition and the Hilbert spectrum for nonlinear and non-stationary time series analysis. Proceedings of the Royal Society of London, Series A, 454, 903-995.

Hurtado, J. M., Rubchinsky, L. L., \& Sigvardt, K. A. (2004). Statistical method for detection of phase-locking episodes in neural oscillations. Journal of Neurophysiology, 91(4), 1883-1898.

Husserl, E. (1991). On the phenomenology of the consciousness of internal time (1893-1917) (J. B. Brough, Trans.). Dordrecht: Kluwer Academic Publishers.

Ioannides, A. A. (2001). Real time human brain function: Observations and inferences from single-trial analysis of magnetoencephalographic signals. Clinical Electroencephalography, 32(3), 98-111.

Ioannides, A. A., Liu, M. J., Liu, L. C., Bamidis, P. D., Hellstrand, E., \& Stephan, K. M. (1995). Magnetic field tomography of cortical and deep processes: Examples of "real-time mapping" of averaged and single trial MEG signals. International Journal of Psychophysiology, 20(3), 161-175. 
Jack, A. I., \& Roepstorff, A. (2002). Introspection and cognitive brain mapping: From stimulus-response to script-report. Trends in Cognitive Sciences, 6(8), 333-339.

James, W. (1981). The principles of psychology. Cambridge, MA: Harvard University Press.

Jensen, O., \& Vanni, S. (2002). A new method to identify multiple sources of oscillatory activity from magnetoencephalographic data. NeuroImage, 15, 568-574.

Jung, T.-P., Makeig, S., Westerfield, M., Townsend, J., Courchesne, E., \& Sejnowski, T. J. (2001). Analysis and visualization of single-trial event-related potentials. Human Brain Mapping, 14, 166-185.

Kelso, S. J. A. (1995). Dynamic patterns: The self-organization of brain and behavior. Cambridge: MIT Press.

Korn, H., \& Faure, P. (2003). Is there chaos in the brain? II. Experimental evidence and related models. Comptes Rendus des Biology, 326(9), 787-840.

Kovacs, I., Papathomas, T. V., Yang, M., \& Feher, A. (1996). When the brain changes its mind: Interocular grouping during binocular rivalry. Proceedings of the National Academy of Sciences of the United States of America, 93, 15508-15511.

Lachaux, J. P., Lutz, A., Rudrauf, D., Cosmelli, D., Le Van Quyen, M., Martinerie, J., et al. (2002). Estimating the time-course of coherence between single-trial brain signals: An introduction to wavelet coherence. Neurophysiologie Clinique, 32(3), $157-174$.

Lachaux, J. P., Rodriguez, E., Le Van Quyen, M., Lutz, A., Martinerie, J., \& Varela, F. J. (2000). Studying single-trials of phase synchronous activity in the brain. International Journal of Bifurcation and Chaos, 10(10), 2429-2439.

Lachaux, J.-P., Rodriguez, E., Martinerie, J., \& Varela, F. J. (1999). Measuring phase synchrony in brain signals. Human Brain Mapping, 8, 194-208.

Lansing, R. W. (1964). Electroencephalographic correlates of binocular rivalry in man. Science, 146, 1325-1327.

Laskaris, N. A., \& Ioannides, A. A. (2001). Exploratory data analysis of evoked response single trials based on minimal spanning tree. Clinical Neurophysiology, 112, 698-712.

Le Van Quyen, M., Focher, J., Lachaux, J. P., Rodriguez, E., Lutz, A., Martinerie, J., et al. (2001). Comparison of Hilbert transform and wavelet methods for the analysis of neuronal synchrony. Journal of Neuroscience Methods, 111, 83-98.

Lehky, S. R. (1995). Binocular rivalry is not chaotic. Proceedings of the Royal Society of London Series A, 259, 71-76.

Leopold, D. A., \& Logothetis, N. K. (1996). Activity changes in early visual cortex reflect monkeys' percepts during binocular rivalry. Nature, 379, 549-553.

Leopold, D. A., \& Logothetis, N. K. (1999). Multistable phenomena: Changing views in perception. Trends in Cognitive Science, 3(7), 254-264.

Lloyd, D. (2002). Functional MRI and the study of human consciousness. Journal of Clinical Neuroscience, 14(6), 818-831.

Logothetis, N. K., Leopold, D. A., \& Sheinberg, D. L. (1996). What is rivaling during binocular rivalry? Nature, 380, 621-624.

Lumer, E. D., Friston, K. J., \& Rees, G. (1998). Neural correlates of perceptual rivalry in the human brain. Science, 280, $1930-1934$.

Lumer, E. D., \& Rees, G. (1999). Co-variation of activity in visual and prefrontal cortex associated with subjective visual perception. Proceedings of the National Academy of Sciences of the United States of America, 96, 1669-1673.

Lutz, A., Lachaux, J.-P., Martinerie, J., \& Varela, F. J. (2002). Guiding the study of brain dynamics by using first-person data: Synchrony patterns correlate with ongoing conscious states during a simple visual task. Proceedings of the National Academy of Sciences of the United States of America, 99, 1586-1591.

Lutz, A., \& Thompson, E. (2003). Neurophenomenology: Integrating subjective experience and brain dynamics in the neuroscience of consciousness. Journal of Consciousness Studies, 10(9-10), 31-52.

Makeig, S., Westerfield, M., Jung, T.-P., Enghoff, S., Townsend, T., Courchesne, E., et al. (2002). Dynamic brain sources of visual evoked responses. Science, 295, 690-694.

Morgan, S. T., Hansen, J. C., \& Hillyard, S. A. (1996). Selective attention to stimulus location modulates the steady-state visual evoked potential. Proceedings of the National Academy of Sciences of the United States of America, 93(10), 4770-4774.

Muller, M. M., Picton, T. W., Valdes-Sosa, P., Riera, J., Teder-Salejarvi, W. A., \& Hillyard, S. A. (1998). Effects of spatial selective attention on the steady-state visual evoked potential in the 20-28 Hz range. Brain Research. Cognitive Brain Research, 6(4), $249-261$.

Muller, M. M., Teder-Salejarvi, W., \& Hillyard, S. A. (1998). The time course of cortical facilitation during cued shifts of spatial attention. Nature Neuroscience, 1(7), 631-634.

Noe, A., \& Thompson, E. (2004). Are there any neural correlates of consciousness? Journal of Consciousness Studies, 11(1), 3-28.

Nunez, P. L., \& Silberstein, R. B. (2000). On the relationship of synaptic activity to macroscopic measurements: Does co-registration of EEG with fMRI make sense? Brain Topography, 13(2), 79-96.

Palus, M., \& Hoyer, D. (1998). Detecting nonlinearity and phase synchronization with surrogate data. IEEE Engineering in Medicine and Biology, 40-45.

Polonsky, A., Blake, R., Braun, J., \& Heeger, D. J. (2000). Neuronal activity in human primary visual cortex correlates with perception during binocular rivalry. Nature Neuroscience, 3(11), 1153-1159.

Rainville, P., \& Price, D. (2003). Hypnosis phenomenology and the neurobiology of consciousness. International Journal of Clinical and Experimental Hypnosis, 51(2), 105-129.

Rees, G., Kreiman, G., \& Koch, C. (2002). Neural correlates consciousness in humans. Nature Reviews Neuroscience, 3, $261-269$.

Rodriguez, E., Georges, N., Lachaux, J-P., Martinerie, J., Renault, B., \& Varela, F. J. (1999). Perception's shadow: Long-distance synchronization of human brain activity. Nature, 397, 430-433.

Schall, J. D., Nawrot, M., Blake, R., \& Yu, K. (1993). Visually guided attention is neutralized when informative cues are visible but unperceived. Vision Research, 33(15), 2057-2064.

Singer, W., Engel, A. K., Kreiter, A. K., Munk, M. H., Neuenschwander, S., \& Roelfsema, P. R. (1997). Neuronal assemblies: Necessity, signature and detectability. Trends in Cognitive Sciences, 1(7), 252-260. 
Tass, P., Rosenblum, M. G., Weule, J., Kurths, J., Pikovsky, A., Volkmann, J., et al. (1998). Detection of n:m phase locking from noisy data: Application to magnetoencephalography. Physical Review Letters, 81, 3291-3294.

Thompson, E. (2007). Mind in life: Biology, phenomenology, and the sciences of mind. Cambridge, MA: Harvard University Press.

Thompson, E., \& Varela, F. J. (2001). Radical embodiment: Neural dynamics and consciousness. Trends in Cognitive Sciences, 5, 418-425.

Tong, F. (2003). Primary visual cortex and visual awareness. Nature Reviews Neuroscience, 4, $219-229$.

Tong, F., \& Engel, S. A. (2001). Interocular rivalry revealed in the human blind-spot representation. Nature, 411, $195-199$.

Tong, F., Nakayama, K., Vaughan, J. T., \& Kanwisher, N. (1998). Binocular rivalry and visual awareness in human extrastriate cortex. Neuron, 21, 753-759.

Tononi, G., Srinivasan, R., Russell, D. P., \& Edelman, G. (1998). Investigating neural correlates of conscious perception by frequencytagged neuromagnetic responses. Proceedings of the National Academy of Sciences of the United States of America, 95, 3198-3203.

Tootell, R. B., Mendola, J. D., Hadjikhani, N. K., Ledden, P. J., Liu, A. K., Reppas, J. B., et al. (1997). Functional analysis of V3A and related areas in human visual cortex. Journal of Neuroscience, 17(18), 7060-7078.

Tootell, R. B., Reppas, J. B., Dale, A. M., Look, R. B., Sereno, M. I., Malach, R., et al. (1995). Visual motion aftereffect in human cortical area MT revealed by functional magnetic resonance imaging. Nature, 375(6527), 139-141.

VanRullen, R., \& Koch, C. (2003). Is perception discrete or continuous? Trends in Cognitive Science, 7(5), 207-213.

Varela, F. J. (1996). Neurophenomenology: A methodological remedy for the hard problem. Journal of Consciousness Studies, 3(4), $330-349$.

Varela, F. J. (1999). The specious present: A neurophenomenology of time consciousness. In J. Petitot, F. J. Varela, B. Pachoud, \& J-M. Roy (Eds.), Naturalizing phenomenology: Issues in contemporary phenomenology and cognitive science (pp. 266-314). Stanford, CA: Stanford University Press.

Varela, F. J., Lachaux, J.-P., Rodriguez, E., \& Martinerie, J. (2001). The Brainweb: Phase synchronization and large-scale integration. Nature Reviews Neuroscience, 2, 229-239.

Vogeley, K., \& Kupke, C. (2007). Disturbances of time consciousness from a phenomenological and a neuroscientific perspective. Schizophrenia Bulletin, 33, 157-165.

Wandell, B. A. (1999). Computational neuroimaging of human visual cortex. Annual Review of Neuroscience, 22, $145-173$.

Wilson, H. R. (2003). Computational evidence for a rivalry hierarchy in vision. Proceedings of the National Academy of Sciences of the United States of America, 100(24), 14499-14503.

Windman, S., Wehrmann, M., Calabrese, P., \& Güntürkün, O. (2006). Role of the prefrontal cortex in attentional control over bistable vision. Journal of Cognitive Neuroscience, 18(3), 456-471.

Zahavi, D. (2003). Inner time-consciousness and pre-reflective self-awareness. In D. Welton (Ed.), The new Husserl: A critical reader (pp. 157-180). Bloomington and Indianapolis, IN: Indiana University Press.

Zahavi, D. (2005). Subjectivity and selfhood: Investigating the first-person perspective. Cambridge, MA: The MIT Press/A Bradford Book. 